\title{
Carcaça e componentes não carcaça de cordeiros terminados em confinamento com caroço de algodão na dieta
}

[Carcass and non carcass components of lambs finished in feedlot with cottonseed on the diet]

\author{
V.M. Pilecco ${ }^{1}$, S. Carvalho ${ }^{1}$, L.G. Pellegrini ${ }^{2}$, R.O. Mello ${ }^{1}$, P.S. Pacheco ${ }^{1}$, \\ A.C.R.S. Pellegrin ${ }^{1}$, A.B. Moro ${ }^{3}$, J.F. Lopes ${ }^{4}$, V.L Mello ${ }^{3}$ \\ ${ }^{1}$ Universidade Federal de Santa Maria - Santa Maria, RS \\ ${ }^{2}$ Instituto Federal Farroupilha - Júlio de Castilhos, RS \\ ${ }^{3}$ Aluno de pós-graduação - Universidade Federal de Santa Maria - Santa Maria, RS \\ ${ }^{4}$ Aluno de pós-graduação - Universidade Federal do Rio Grande do Sul - Porto Alegre, RS
}

\section{RESUMO}

O objetivo deste estudo foi avaliar as características de carcaça e dos componentes não carcaça de cordeiros terminados em confinamento, com diferentes proporções de caroço de algodão na dieta. Foram utilizados 45 cordeiros, machos, não castrados, da raça Ile de France. Os tratamentos foram constituídos por níveis de inclusão de caroço de algodão na matéria seca (MS) da dieta total (0\%; 10\%; 20\%; 30\% ou 40\%), sendo a dieta composta por silagem de milho (Zea mays L.), grão de milho triturado (Zea mays L.), farelo de soja (Glycine max L.), caroço de algodão (Gossypium hirsutum L.), calcário calcítico e sal mineral, em proporção de volumoso:concentrado de 40:60. Os animais foram abatidos com peso de abate preestabelecido. O peso de carcaça quente e o peso de carcaça fria, bem como o índice de quebra ao resfriamento, o índice de compacidade, a conformação e o estado de engorduramento da carcaça, não foram influenciados $(\mathrm{P}>0,05)$ pelo nível de inclusão de caroço de algodão na dieta. As características de rendimento de carcaça quente e rendimento de carcaça fria diminuíram linearmente $(\mathrm{P} \leq 0,05)$ à medida que se incluiu caroço de algodão na dieta. Com relação à medida de espessura de gordura de cobertura, pode-se observar que houve comportamento quadrático crescente e, em relação à variável área de olho de lombo, o comportamento observado foi o linear decrescente. Quanto às proporções dos cortes comerciais da carcaça, o peso de perna diminuiu linearmente $(\mathrm{P} \leq 0,05)$ enquanto a porcentagem de perna foi influenciada de forma quadrática $(\mathrm{P} \leq 0,05)$ pela inclusão de caroço de algodão nas dietas. $\mathrm{O}$ trato gastrointestinal cheio e o conteúdo do trato gastrointestinal aumentam linearmente $(\mathrm{P} \leq 0,05)$ com o incremento do nível de inclusão de caroço de algodão na dieta. Algumas das características de carcaça e dos componentes não carcaça tiveram influência negativa da elevação do teor de fibra e de lipídios da dieta à medida que se incluiu caroço de algodão na dieta total.

Palavras-chave: abate, carne ovina, cortes comerciais, rendimento

\begin{abstract}
The objective of this study was to evaluate the carcass and non carcass components characteristics of lambs finished in feedlot with different proportions of cottonseed on the diet. Forty five lambs, non castrated males, from Ile de France race. The treatments were constituted by levels of inclusion of cottonseed on dry matter (DM) of the total diet (0\%; 10\%; 20\%; 30\% or 40\%), being the diet composed by corn silage (Zea mays L.), ground corn grain (Zea mays L.), soybean meal (Glycine max L.), cottonseed (Gossypiumhirsutum L.), limestone and mineral salt in a roughage: concentrate proportion of 40:60. The animals were slaughtered with a pre-established slaughter weight. The hot and cold carcass weight, as well as the carcass chilling index, the compactness index, the conformation and the fattening state of the carcass were not influenced $(P>0.05)$ by the level of inclusion of cottonseed on the diet. The hot and cold carcass yield decreased linearly $(P \leq 0.05)$ as the cottonseed was included on the diet. Regarding the subcutaneous fat thickness it is possible to observe that there was a crescent quadratic behavior and in relation to the rib eye area variable, the behavior observed was linear decrescent. Regarding the proportions of the commercial cuts of the carcass, the leg weight decreased
\end{abstract}

Recebido em 27 de setembro de 2016

Aceito em 3 de fevereiro de 2018

*Autor para correspondência (corresponding author)

E-mail: scarvalhoufsm@hotmail.com 


\section{Pilecco et al.}

linearly $(P \leq 0.05)$ while the percentage of leg was quadratic influenced $(P \leq 0.05)$ by the inclusion of cottonseed on the diets. The full gastrointestinal tract and the gastrointestinal tract content increased linearly $(P \leq 0.05)$ with the increase on the level of inclusion of cottonseed on the diet. Some of the carcass and non carcass components characteristics had negative influence of level fiber content and dietary lipids as it included cottonseed in the total diet.

Keywords: commercial cuts, sheep meat, slaughter, yield

\section{INTRODUÇÃO}

A ovinocultura de corte é uma atividade que está em constante crescimento no Brasil, pois, segundo Viana e Silveira (2009), o aumento do poder aquisitivo da população e o abate de animais jovens trouxeram um novo mercado para a ovinocultura. Existe, porém, um entrave na oferta desse produto, que impede que o consumo de carne ovina seja fidelizado entre a população. A terminação de ovinos exclusivamente a pasto tem se mostrado ineficaz na regularidade da oferta de animais para abate, por estar sujeita às alterações na disponibilidade de forragem, decorrente das distintas condições climáticas encontradas no país durante o ano. Diante desse impasse, o uso do sistema de confinamento mostra-se uma alternativa viável. Outro aspecto a ser considerado em relação ao sistema de confinamento é que a intensificação do sistema produtivo faz com que ocorra uma redução na idade de abate dos animais e um melhor acabamento das carcaças.

Entretanto, entre os problemas enfrentados na utilização do confinamento, encontra-se o custo de alimentação dos animais, que é, sem dúvida, aquele mais expressivo de todo o sistema. Dessa maneira, faz-se necessária a utilização de alimentos que possam reduzir esse custo sem prejudicar o desempenho dos animais.

O caroço de algodão, um subproduto da indústria têxtil, apresenta-se como uma opção, visto que é encontrado em diversas partes do país e tem baixo custo nas regiões produtoras, favorecendo sua utilização no confinamento. Trata-se de um alimento com elevado valor proteico e energético, podendo ser uma excelente alternativa para substituir os alimentos comumente utilizados nas dietas de ovinos.

Em ovinocultura, a carne é o principal produto de comercialização nos grandes centros consumidores. Dessa forma, a carcaça é o elememto que é levado em consideração no momento de produção desses animais. Contudo, a grande proporção de fibra e de lipídios presente no caroço de algodão pode acabar influenciando negativamente algumas características da carcaça quando esse alimento for adicionado em grande quantidade à dieta.

Deve-se ter atenção, também, ao peso dos componentes não pertencentes à carcaça, o qual, segundo Carvalho et al. (2007), pode representar até $60 \%$ do peso do ovino e a sua valorização comercial poderá proporcionar uma fonte de renda alternativa para o ovinocultor.

Assim, este trabalho foi conduzido com o objetivo de se avaliarem as características de carcaça e dos componentes não carcaça de cordeiros terminados em confinamento, com diferentes proporções de caroço de algodão na dieta.

\section{MATERIAL E MÉTODOS}

O trabalho foi realizado no Instituto Federal de Educação, Ciência e Tecnologia Farroupilha/RS, Campus Júlio de Castilhos, localizado na cidade de Júlio de Castilhos - RS, na localidade denominada São João do Barro Preto. O município está situado em uma altitude de 513 metros, latitude de $29^{\circ} 18^{\prime} 35^{\prime \prime}$ sul e longitude de 5371'23" oeste. As análises bromatológicas foram realizadas no Laboratório de Bromatologia e Nutrição de Ruminantes, pertencente ao Departamento de Zootecnia da Universidade Federal de Santa Maria. O trabalho foi aprovado pela Comissão de Ética no Uso de Animais do Instituto Federal Farroupilha, protocolo número 01.0378.2015/001.2015.

Foram utilizados 45 cordeiros, machos não castrados, da raça Ile de France, desmamados com aproximadamente 60 dias de idade. Os animais foram confinados em baias individuais, cobertas, no nível do solo, com cama sobreposta de maravalha, com dimensão de $2 \mathrm{~m}^{2}$ por animal. Todas as baias eram providas de comedouros e 
bebedouros individuais. $\mathrm{O}$ delineamento experimental utilizado foi o inteiramente ao acaso, com cinco tratamentos e nove repetições.

Os tratamentos foram constituídos por níveis de inclusão de caroço de algodão na matéria seca (MS) da dieta total $(0 \% ; 10 \% ; 20 \% ; 30 \%$ ou $40 \%$ ), sendo a dieta composta por silagem de milho (Zea mays L.), grão de milho triturado (Zea mays L.), farelo de soja (Glycine max L.), caroço de algodão (Gossypium hirsutum L.), calcário calcítico e sal mineral, em uma proporção de volumoso:concentrado de 40:60. A composição química do sal mineral utilizada era: cálcio: $145 \mathrm{~g}$; fósforo: $85 \mathrm{~g}$; magnésio: $10 \mathrm{~g}$; sódio: $135 \mathrm{~g}$; enxofre: $18 \mathrm{~g}$; iodo: $80 \mathrm{mg}$; manganês: $1.400 \mathrm{mg}$; molibdênio: $150 \mathrm{mg}$; selênio: $25 \mathrm{mg}$; cobalto: $60 \mathrm{mg}$; zinco: $4.000 \mathrm{mg}$. As dietas foram formuladas para serem isoproteicas, de acordo com o NRC (Nutrient..., 2007), de modo a atender as exigências nutricionais de cordeiros de maturidade tardia, em crescimento.
Na Tab. 1, é apresentada a composição bromatológica dos ingredientes utilizados na formulação das dietas, e na Tab. 2, a proporção dos ingredientes e a composição bromatológica das dietas experimentais.

O alimento foi fornecido, ad libitum, duas vezes ao dia, sendo os horários de arraçoamento às sete $\mathrm{e}$ às 16 horas. A quantidade oferecida foi ajustada em função da sobra observada diariamente, sendo esta estipulada em $15 \%$ da quantidade oferecida no dia anterior, de modo a garantir o consumo voluntário máximo dos animais.

Ao atingirem o peso de abate preestabelecido em $60 \%$ do peso vivo adulto de suas mães, segundo recomendações de Butterfield (1988), os cordeiros foram submetidos a um jejum de 12 horas e, em seguida, pesados, insensibilizados e abatidos mediante sangria.

Tabela 1. Composição bromatológica dos alimentos utilizados para a formulação das dietas experimentais

\begin{tabular}{ccccccc}
\hline Item $(\%)$ & $\begin{array}{c}\text { Silagem de } \\
\text { milho }\end{array}$ & $\begin{array}{c}\text { Caroço de } \\
\text { algodão }\end{array}$ & $\begin{array}{c}\text { Milho } \\
\text { quebrado }\end{array}$ & $\begin{array}{c}\text { Farelo de } \\
\text { soja }\end{array}$ & $\begin{array}{c}\text { Calcário } \\
\text { calc. }\end{array}$ & Sal mineral \\
\hline MS & 44,04 & 88,35 & 83,26 & 86,63 & 98 & 98 \\
MO & 89,90 & 95,50 & 96,87 & 92,12 & ----- & ----- \\
PB & 7,52 & 23,26 & 9,14 & 45,12 & ----- & ---- \\
EE & 3,24 & 22,68 & 3,37 & 2,41 & ----- & ---- \\
FDN & 52,93 & 43,84 & 9,26 & 18,84 & ---- & ---- \\
FDA & 27,83 & 26,93 & 1,48 & 8,31 & ---- & ---- \\
LDA & 3,18 & 5,73 & NC2 & NC2 & ----- & ---- \\
CHT & 79,14 & 49,56 & 84,36 & 44,59 & ---- & ---- \\
CNF & 26,21 & 5,72 & 75,10 & 25,75 & ---- & 98 \\
CIN & 10,10 & 4,50 & 3,13 & 7,88 & 98 & 0 \\
NDT & 64,27 & 81,92 & 87,24 & 81,54 & 0 & 14,5 \\
Ca & 0,4 & 0,14 & 0,02 & 0,38 & 34 & 0,5 \\
P & 0,27 & 0,64 & 0,3 & 0,71 & 0 & \\
\hline
\end{tabular}

'Valor tabelado (Valadares Filho et al., 2010).

No momento de cada abate, foi coletado todo o sangue e foram retirados pele, patas, cabeça, pênis e testículos (denominados órgãos externos); coração, rins, fígado, pulmões, traqueia, esôfago, baço, diafragma e pâncreas (denominados órgãos internos); gordura renal, gordura ruminal e gordura do coração (denominadas gorduras internas), os quais foram pesados separadamente. Foram também pesados, individualmente, rúmen-retículo, omaso, abomaso, intestino delgado e intestino grosso, sendo esses órgãos pesados cheios (denominados órgãos gastrointestinais cheios). Em seguida, foi realizado o esvaziamento e a lavagem dos diferentes compartimentos, os quais, após escorrimento da água, foram pesados novamente (denominados órgãos gastrointestinais vazios). Por diferença, obteve-se o peso do conteúdo de cada órgão constituinte do trato gastrointestinal. Pelo somatório dos conteúdos de cada órgão, obteve-se o conteúdo gastrointestinal total (CGITOT). Em seguida, foi calculada a porcentagem dos diferentes órgãos internos em relação ao peso vivo ao abate (PVA) dos animais. 


\section{Pilecco et al.}

Tabela 2. Proporção dos ingredientes e composição bromatológica das dietas experimentais

\begin{tabular}{|c|c|c|c|c|c|}
\hline & \multicolumn{5}{|c|}{ Proporção de caroço de algodão na dieta } \\
\hline & 0 & 10 & 20 & 30 & 40 \\
\hline Dietas & \multicolumn{5}{|c|}{$\% \mathrm{MS}$} \\
\hline Silagem de milho & 40,00 & 40,00 & 40,00 & 40,00 & 40,00 \\
\hline Caroço de algodão & 0,00 & 10,00 & 20,00 & 30,00 & 40,00 \\
\hline Milho & 32,54 & 26,02 & 19,52 & 12,92 & 6,55 \\
\hline Farelo de soja & 25,00 & 21,50 & 18,00 & 14,60 & 11,00 \\
\hline Calcário calcítico & 1,96 & 1,92 & 1,92 & 1,92 & 1,95 \\
\hline Sal mineral & 0,50 & 0,56 & 0,56 & 0,56 & 0,50 \\
\hline \multirow[t]{2}{*}{$\sum$} & 100,00 & 100,00 & 100,00 & 100,00 & 100,00 \\
\hline & \multicolumn{5}{|c|}{ Composição bromatológica (\% MS) } \\
\hline MS & 68,72 & 69,09 & 69,48 & 69,88 & 70,29 \\
\hline MO & 90,51 & 90,52 & 90,55 & 90,58 & 90,64 \\
\hline PB & 17,26 & 17,41 & 17,57 & 17,75 & 17,87 \\
\hline $\mathrm{EE}$ & 3,00 & 4,96 & 6,92 & 8,89 & 10,85 \\
\hline FDN & 28,90 & 32,02 & 35,14 & 38,27 & 41,39 \\
\hline FDA & 13,69 & 16,00 & 18,30 & 20,62 & 22,92 \\
\hline CHT & 70,25 & 68,15 & 66,06 & 63,93 & 61,91 \\
\hline $\mathrm{CNF}$ & 41,36 & 36,13 & 30,92 & 25,66 & 20,52 \\
\hline CIN & 9,38 & 9,35 & 9,32 & 9,30 & 9,26 \\
\hline NDT & 74,48 & 74,13 & 73,80 & 73,46 & 73,16 \\
\hline $\mathrm{Ca}$ & 0,98 & 0,98 & 0,98 & 0,98 & 0,98 \\
\hline $\mathrm{P}$ & 0,43 & 0,45 & 0,46 & 0,48 & 0,50 \\
\hline
\end{tabular}

Após cada abate, a carcaça foi pesada individualmente e, em seguida, resfriada por 24 horas em câmara frigorífica, em uma temperatura de $4^{\circ} \mathrm{C}$, e pesada novamente para determinação do peso da carcaça fria. Foram observadas as seguintes características em relação às carcaças dos cordeiros: peso da carcaça quente, peso da carcaça fria, índice de quebra ao resfriamento, índice de compacidade da carcaça, rendimento de carcaça quente e rendimento de carcaça fria. $\mathrm{Na}$ carcaça fria de cada animal, foi avaliada a conformação e o estado de engorduramento. Logo após, as carcaças foram divididas, em duas metades, com auxílio de serra elétrica, longitudinalmente. $\mathrm{Na}$ metade esquerda da carcaça, foi obtida a área de olho de lombo pela exposição do músculo Longissimus dorsi após um corte transversal na carcaça, entre a $12^{\mathrm{a}}$ e a $13^{\mathrm{a}}$ costela, traçando o seu contorno em papel vegetal (Müller, 1980). Para determinação e registro da área, foi utilizado o programa SITER 3.1, modelo A2, descrito por Giotto (2001). Na mesma região do músculo, foi tomada a espessura de gordura de cobertura com o uso de paquímetro (Osório et al., 1998).
Simultaneamente às medidas realizadas na metade esquerda da carcaça, a metade direita da carcaça foi pesada e separada regionalmente, segundo procedimentos descritos por Osório et al. (1998), nos seguintes cortes comerciais: pescoço, paleta, costilhar e perna. Após a separação, os diferentes cortes comerciais foram pesados, e sua porcentagem calculada em relação ao peso da carcaça fria.

O delineamento experimental utilizado foi $\mathrm{o}$ inteiramente ao acaso, e na avaliação das cinco dietas experimentais, foram utilizadas nove repetições. Os resultados foram submetidos à análise de variância e de regressão. As equações foram selecionadas com base nos coeficientes de determinação e na significância dos coeficientes de regressão, adotando-se o nível de 5\% de probabilidade, mediante a utilização do teste F. Os dados coletados foram submetidos ao teste de normalidade (Shapiro-Wilk). As análises foram realizadas utilizando-se o pacote estatístico SAS (2004). O mesmo programa foi empregado no estudo de correlação entre as variáveis 
dependentes, por meio do cálculo dos coeficientes de correlação de Pearson.

\section{RESULTADOS E DISCUSSÃO}

Verifica-se, na Tab. 3, que tanto o peso vivo ao abate (PVA) quanto o peso de carcaça quente (PCQ) e o peso de carcaça fria (PCF) não foram influenciados $(\mathrm{P}>0,05)$ pelo nível de inclusão de caroço de algodão na dieta. Esse resultado pode ser explicado pelo fato de os animais serem abatidos com um peso preestabelecido, além de serem do mesmo genótipo, sexo e de idade semelhante, comprovando, assim, a uniformidade do lote de animais utilizados neste estudo.

As variáveis de rendimento de carcaça quente (RCQ) e rendimento de carcaça fria $(\mathrm{RCF})$ diminuíram linearmente à medida que se incrementou o teor de caroço de algodão na dieta dos animais. Sabe-se que o conteúdo do trato gastrointestinal é uma característica que influencia diretamente nos rendimentos de carcaça, e similar a este estudo, Pires et al. (2006) também observaram redução linear dos rendimentos de carcaça à medida que se aumentavam os teores de FDN da dieta. Nesse sentido, esse resultado é explicado pelo aspecto de que à medida que se aumentou a inclusão de caroço de algodão na dieta, ocorreu aumento dos teores de fibra (Tab. 2) e, consequentemente, redução da taxa de passagem e aumento do tempo de permanência do alimento no trato gastrintestinal dos animais (Tab. 5), aspecto esse que influenciou negativamente sobre o RCQ e o RCF que foram obtidos. Essa afirmativa é embasada pelos altos coeficientes de correlação obtidos entre RCQ e conteúdo do trato gastrointestinal (CTGIT) $(\mathrm{r}=-0,70 ; \mathrm{P} \leq 0,0001) \mathrm{e}$ RCF e CTGIT ( $r=-0,73 ; P \leq 0,0001)$.

Tabela 3. Valores médios para peso vivo ao abate (PVA), peso de carcaça quente (PCQ), peso de carcaça fria $(\mathrm{PCF})$, rendimento de carcaça quente $(\mathrm{RCQ})$, rendimento de carcaça fria $(\mathrm{RCF})$, índice de quebra ao resfriamento (IQ), índice de compacidade da carcaça (ICC), conformação da carcaça (CCAR), estado de engorduramento (EENG), espessura de gordura (EGOR) e área de olho de lombo (AOL), de acordo com os tratamentos

\begin{tabular}{|c|c|c|c|c|c|c|c|c|}
\hline \multicolumn{9}{|c|}{ \% de caroço de algodão } \\
\hline & 0 & 10 & 20 & 30 & 40 & ER & $\mathrm{CV}$ & $\mathrm{P}>\mathrm{F}$ \\
\hline PVA (kg) & 34,43 & 34,22 & 34,74 & 34,87 & 34,48 & $\bar{Y}=34,56$ & 2,5 & 0,4579 \\
\hline PCQ (kg) & 16,10 & 16,25 & 15,55 & 16,00 & 15,45 & $\bar{Y}=15,87$ & 5,9 & 0,1299 \\
\hline PCF (kg) & 15,49 & 15,67 & 15,07 & 15,35 & 14,84 & $\bar{Y}=15,28$ & 5,9 & 0,1020 \\
\hline $\operatorname{RCQ}(\%)$ & 46,73 & 46,73 & 44,77 & 45,86 & 44,83 & 1 & 4,2 & 0,0275 \\
\hline $\mathrm{RCF}(\%)$ & 44,96 & 45,04 & 43,37 & 44,01 & 43,06 & 2 & 4,1 & 0,0149 \\
\hline IQ (\%) & 3,79 & 3,61 & 3,10 & 4,05 & 3,95 & $\bar{Y}=3,70$ & 39,1 & 0,2389 \\
\hline $\operatorname{ICC}(\%)$ & 0,27 & 0,28 & 0,26 & 0,27 & 0,26 & $\bar{Y}=0,27$ & 5,6 & 0,0904 \\
\hline CCAR (1-5) & 2,94 & 3,05 & 2,94 & 3,11 & 3,05 & $\bar{Y}=3,02$ & 11,7 & 0,4615 \\
\hline EENG (1-5) & 2,94 & 3,00 & 3,11 & 3,17 & 3,00 & $\bar{Y}=3,04$ & 8,3 & 0,1201 \\
\hline EGOR (mm) & 1,32 & 1,84 & 1,68 & 1,74 & 1,37 & 3 & 32,9 & 0,0226 \\
\hline $\mathrm{AOL}\left(\mathrm{cm}^{2}\right)$ & 14,39 & 15,07 & 14,62 & 12,59 & 12,38 & 4 & 7,0 & 0,0020 \\
\hline
\end{tabular}

Com relação ao índice de quebra ao resfriamento (IQ), pode-se observar que essa variável não foi influenciada significativamente $(\mathrm{P}>0,05)$ pela inclusão de caroço de algodão nas dietas, que apresentou valor médio de 3,70. De acordo com Lima et al. (2013), esse valor é considerado aceitável dentro dos níveis máximos de perdas ao resfriamento para cordeiros, que variam de 3 a $4 \%$. Tal resultado pode ser explicado pelo fato de os animais, independentemente do nível de inclusão de caroço de algodão, apresentarem adequado grau de acabamento na carcaça, como pode ser observado na Tab. 3 , pelo estado de engorduramento da carcaça $(3,04$, em uma escala de 1 a 5). Segundo Osório et al. (1998), um nível adequado de gordura na carcaça contribui positivamente para diminuição da perda de líquidos, o que evita o encurtamento das fibras 
musculares e o escurecimento da carne, durante o processo de resfriamento.

O índice de compacidade da carcaça (ICC) também não foi influenciado $(\mathrm{P}>0,05)$ pelo nível de inclusão de caroço de algodão, sendo essa variável determinada utilizando-se o PCF e o comprimento da carcaça dos animais. Como os cordeiros não diferiram em relação ao peso de carcaça fria e, conforme comentado anteriormente, apresentavam características semelhantes (peso de abate, genótipo, sexo e idade), também apresentavam similaridade quanto ao comprimento de carcaça, o que fez com que o ICC fosse semelhante entre os animais.

A conformação da carcaça (CCAR) não foi influenciada $(\mathrm{P}>0,05)$ pelo nível de inclusão de caroço de algodão da dieta, sendo esse resultado explicado pelo critério de abate utilizado, em que os cordeiros foram abatidos com peso vivo semelhante, e pelo fato de que os animais eram do mesmo genótipo. Além disso, independentemente do nível de caroço de algodão utilizado, as dietas foram formuladas, segundo o NRC (Nutrient..., 2007), para atender as exigências nutricionais dos animais e garantir um adequado desenvolvimento dos cordeiros.

Com relação à espessura de gordura de cobertura (EGOR), observa-se que houve comportamento quadrático crescente. Pode-se explicar esse comportamento por ele estar associado ao que ocorreu com o consumo de matéria seca (CMS $\left.(\mathrm{kg} / \mathrm{dia})=1,03084+0,01102 \mathrm{CA}-0,00026 \mathrm{CA}^{2}\right)$, de proteína bruta $(\mathrm{CPB}(\mathrm{kg} / \mathrm{dia})=0,16389+$ $\left.0,00222 \mathrm{CA}-0,00005 \mathrm{CA}^{2}\right)$ e de nutrientes digestíveis totais $(\mathrm{CNDT}(\mathrm{kg} / \mathrm{dia})=0,68358+$ $\left.0,00728 \mathrm{CA}-0,00019 \mathrm{CA}^{2}\right)$, ou seja, até certo nível, ocorreu efeito positivo da inclusão do caroço de algodão, efeito esse atribuído à maior preferência por esse alimento na dieta, que, incluído até esses níveis, fez com que o consumo e o ganho de peso $(\mathrm{GMD}(\mathrm{kg} / \mathrm{dia})=0,25826+$ $0,00472 \mathrm{CA}-0,00011246 \mathrm{CA}^{2}$ ) crescessem, afetando positivamente a deposição de gordura de cobertura. Nos níveis mais altos de inclusão de caroço de algodão, os valores de extrato etéreo ultrapassaram os valores estipulados como referência para que não afetassem a digestibilidade da dieta, que, segundo Koslosky
(2011), é de até 7\% da MS total. Além disso, os valores de FDN e FDA são altos e, conforme Araújo et al. (1998), o animal consome alimento até atingir a capacidade máxima de ingestão de FDN, que passa a inibi-la, havendo, assim, um limite de distensão ruminal que determina a interrupção da ingestão do alimento. Dessa maneira, uma limitação de consumo afetou negativamente a característica de deposição de gordura (EGOR) nos níveis mais altos de inclusão desse alimento na dieta.

Verifica-se que houve diferença significativa para a variável de área de olho de lombo (AOL), em que, à medida que se incluiu caroço de algodão na dieta, a variável apresentou comportamento linear decrescente. A AOL é uma medida representativa da proporção de músculo presente no animal. Assim, pode-se explicar esse comportamento em razão da menor deposição de tecido à medida que se incluiu caroço de algodão na dieta, provavelmente justificado pelos elevados níveis de lipídios e de fibra na dieta, que influenciaram negativamente no consumo e no desempenho dos animais, refletindo na característica de carcaça de AOL.

Em concordância a esse resultado, Cunha et al. (2008), ao avaliarem cordeiros da raça Santa Inês, terminados com níveis de inclusão de caroço de algodão, também observaram efeito linear decrescente pra AOL, com valores que variaram de $8,6 \mathrm{~cm}^{2}$, no nível mais alto de inclusão, a $11,3 \mathrm{~cm}^{2}$, no tratamento sem inclusão de caroço de algodão. Esses valores ainda estão inferiores aos observados neste trabalho, que foram de $12,38 \mathrm{~cm}^{2}$ para o maior nível de inclusão de caroço de algodão e de $14,39 \mathrm{~cm}^{2}$ para o tratamento controle, podendo essa diferença entre os estudos ser explicada pelos distintos genótipos avaliados.

Na Tab. 4, pode-se observar, que, para a maioria dos cortes comerciais avaliados. não houve efeito significativo $(\mathrm{P}>0,05)$ do nível de inclusão de caroço de algodão. A variável perna (PERN), expressa em $\mathrm{kg}$, apresentou comportamento linear decrescente com a inclusão de caroço de algodão na dieta. A mesma variável, expressa em $\%$, apresentou comportamento quadrático decrescente. 
Tabela 4. Valores médios para pesos e porcentagens de pescoço (PESC), paleta (PALET), costilhar (COST) e perna (PERN), de acordo com os tratamentos

\begin{tabular}{|c|c|c|c|c|c|c|c|c|}
\hline & \multicolumn{5}{|c|}{ \% de caroço de algodão } & \multirow[b]{2}{*}{ ER } & \multirow[b]{2}{*}{$\mathrm{CV}$} & \multirow[b]{2}{*}{$P>F$} \\
\hline & 0 & 10 & 20 & 30 & 40 & & & \\
\hline PESC (kg) & 0,54 & 0,58 & 0,58 & 0,53 & 0,53 & $\overline{\mathrm{Y}}=0,55$ & 10,7 & 0,1059 \\
\hline PALET $(\mathrm{kg})$ & 1,69 & 1,71 & 1,62 & 1,67 & 1,61 & $\bar{Y}=1,66$ & 7,4 & 0,1457 \\
\hline COST (kg) & 2,75 & 2,84 & 2,80 & 2,76 & 2,62 & $\bar{Y}=2,75$ & 7,4 & 0,0820 \\
\hline PERN (kg) & 2,67 & 2,63 & 2,51 & 2,57 & 2,50 & 1 & 6,8 & 0,0390 \\
\hline $\operatorname{PESC}(\%)$ & 7,14 & 7,44 & 7,76 & 7,04 & 7,32 & $\bar{Y}=7,34$ & 9,0 & 0,2039 \\
\hline PALET (\%) & 22,06 & 22,00 & 21,54 & 22,21 & 22,16 & $\bar{Y}=21,99$ & 4,5 & 0,3624 \\
\hline $\operatorname{COST}(\%)$ & 35,95 & 36,62 & 37,31 & 36,52 & 36,11 & $\overline{\mathrm{Y}}=36,50$ & 4,3 & 0,0712 \\
\hline PERN (\%) & 34,84 & 33,94 & 33,39 & 34,23 & 34,41 & 2 & 3,4 & 0,0198 \\
\hline
\end{tabular}

1. $\hat{\mathrm{Y}}=2,65444-0,00391 \mathrm{CA}, \mathrm{R}^{2}=0,09 ; 2 . \hat{\mathrm{Y}}=34,78235-0,10698 \mathrm{CA}+0,00253 \mathrm{CA}^{2}, \mathrm{R}^{2}=0,13$.

Na Tab. 5, verifica-se que a quantidade de fibra presente no caroço de algodão e o excesso de lipídios nos níveis mais altos de inclusão na dieta influenciaram significativamente no aumento do volume dos órgãos gastrointestinais cheios (ORGGICT) e também do conteúdo gastrointestinal total (CGITOT), que apresentaram comportamento linear crescente. Corroborando com esta pesquisa, Medeiros et al. (2008) relataram maior conteúdo do trato gastrointestinal em ovinos alimentados com maior proporção de volumoso na dieta. Também se pode observar que o compartimento do trato gastrointestinal que teve maior quantidade de conteúdo foi o rúmen-retículo (CRUMRET), apresentando comportamento linear crescente, à medida que se incluía caroço de algodão na dieta. Explica-se esse comportamento pelo fato de o rúmen-retículo ser o compartimento mais relacionado com a digestão dos alimentos fibrosos e por essa digestão ser mais lenta à medida que aumenta a quantidade de fibra da dieta.

Tabela 5. Componentes não carcaça, expressos em \% do peso vivo, de acordo com os tratamentos

\begin{tabular}{|c|c|c|c|c|c|c|c|c|}
\hline & \multicolumn{5}{|c|}{ \% de caroço de algodão } & \multirow[b]{2}{*}{ ER } & \multirow[b]{2}{*}{$\mathrm{CV}$} & \multirow[b]{2}{*}{$\mathrm{P}>\mathrm{F}$} \\
\hline & 0 & 10 & 20 & 30 & 40 & & & \\
\hline ORGEXT & 21,76 & 22,01 & 21,67 & 21,33 & 21,61 & $\bar{Y}=21,68$ & 7,1 & 0,5516 \\
\hline ORGINT & 4,92 & 5,15 & 4,98 & 4,87 & 4,81 & $\bar{Y}=4,95$ & 5,9 & 0,1170 \\
\hline GORDINT & 1,40 & 1,54 & 1,20 & 1,34 & 1,47 & $\overline{\mathrm{Y}}=1,40$ & 17,5 & 0,1937 \\
\hline ORGGIC & 21,38 & 21,19 & 23,70 & 24,18 & 25,03 & 1 & 9,9 & 0,0002 \\
\hline ORGGIV & 7,04 & 6,82 & 7,09 & 6,63 & 6,82 & $\bar{Y}=6,88$ & 6,1 & 0,1638 \\
\hline CGITOT & 14,30 & 14,37 & 16,60 & 17,55 & 18,21 & 2 & 13,5 & $<0,0001$ \\
\hline CRUMRET & 3,36 & 3,04 & 3,68 & 4,01 & 4,05 & 3 & 21,7 & 0,0074 \\
\hline COMASO & 0,08 & 0,09 & 0,08 & 0,09 & 0,09 & $\bar{Y}=0,09$ & 38,8 & 0,4992 \\
\hline CABOM & 0,47 & 0,41 & 0,46 & 0,44 & 0,51 & $\overline{\mathrm{Y}}=0,46$ & 33,6 & 0,3358 \\
\hline CID & 0,53 & 0,62 & 0,66 & 0,61 & 0,69 & 4 & 20,2 & 0,0215 \\
\hline CIG & 0,83 & 0,83 & 0,88 & 0,97 & 0,93 & 5 & 14,6 & 0,0191 \\
\hline
\end{tabular}

(ORGEXT) órgãos externos; (ORGINT) órgãos internos; (GORDINT) gorduras internas; (ORGGIC) órgãos gastrointestinais cheios; (ORGGIV) órgãos gastrointestinais vazios; (CGITOT) conteúdo gastrointestinal total; (CRUMRET) conteúdo do rúmen-retículo; (COMASO) conteúdo do omaso; (CABOM) conteúdo do abomaso; (CID) conteúdo do intestino delgado; (CIG) conteúdo do intestino grosso.

1. $\hat{Y}=21,01214+0,10386 C A, R^{2}=0,29 ; 2 . \hat{Y}=13,98690+0,11075 C A, R^{2}=0,34 ; 3 . \hat{Y}=3,16178+0,02335 C A$, $\mathrm{R}^{2}=0,15 ; 4 . \hat{\mathrm{Y}}=0,56071+0,00318 \mathrm{CA}, \mathrm{R}^{2}=0,12 ; 5 . \hat{\mathrm{Y}}=0,82387+0,00334 \mathrm{CA}, \mathrm{R}^{2}=0,12$. 


\section{CONCLUSÕES}

Nos níveis mais altos de inclusão de caroço de algodão, a grande quantidade de fibras e o excesso de lipídios na dieta influenciam negativamente as características de rendimento de carcaça quente e fria, a espessura de gordura e a área de olho de lombo, além de proporcionar aumento na proporção dos órgãos gastrointestinais cheios e do conteúdo do trato gastrointestinal.

\section{REFERÊNCIAS}

ARAÚJO, G.G.L.; SILVA, J.F.C.; VALADARES FILHO, S.C. et al. Consumo e digestibilidade total dos nutrientes de dietas contendo diferentes níveis de volumoso, em bezerros. Rev. Bras. Zootec., v.27, p.345-354, 1998.

BUTTERFIELD, R. New concept of sheep growth. Sydney: Sydney University Press, 1988. $167 \mathrm{p}$.

CARVALHO, S.; BROCHIER, M.A.; PIVATO, J. et al. Ganho de peso, características da carcaça e componentes não-carcaça de cordeiros da raça Texel terminados em diferentes sistemas alimentares. Ciênc. Rural, v.37, p.821-827, 2007.

CUNHA, M.D.G.G.; CARVALHO, F.F.R.; GONZAGA NETO, S.; CEZAR, M.F. Características quantitativas de carcaça de ovinos Santa Inês confinados alimentados com rações contendo diferentes níveis de caroço de algodão integral. Rev. Bras. Zootec., v.37, p.1112-1120, 2008.

GIOTTO, E. Manual siter 3.1. Santa Maria: Universidade Federal de Santa Maria, 2001. $187 \mathrm{p}$.
KOZLOSKI, G.V. Bioquímica dos ruminantes. 3.ed. Santa Maria: UFSM, 2011. 216p.

LIMA, L.D.; RÊGO. F.C.A.; JUNIOR, C.K. et $a l$. Interferência da dieta de alto grão sobre as características da carcaça e carne de cordeiros Texel. Semin. Ciênc. Agrar., v.34, p.4053-4064, 2013.

MEDEIROS, G.R.; CARVALHO, F.F.R.; FERREIRA, M.A. et al. Efeito dos níveis de concentrado sobre os componentes não-carcaça de ovinos Morada Nova em confinamento. Rev. Bras. Zootec., v.37, p.1063-1071, 2008.

MÜLLER, L. Normas para avaliação de carcaça e concurso de carcaças de novilhos. Santa Maria: Universidade Federal de Santa Maria, 1980. 31p.

NUTRIENT requirement of small ruminants: Sheep, goats, cervids and new camelids. Washington: National Academy Press, 2007. $384 p$.

OSÓRIO, J.C.S. et al. Métodos para avaliação da produção de carne ovina: 'in vivo', na carcaça e na carne. Pelotas: UFPEL, 1998. 98p.

PIRES, C.C.; GALVANI, D.B.; CARVALHO, S. et al. Características da carcaça de cordeiros alimentados com dietas contendo diferentes níveis de fibra em detergente neutro. Rev. Bras. Zootec., v.35, p.2058-2065, 2006.

SAS user's guide, version 9.1. Cary: SAS, 2004. 5135p.

VIANA, J.G.A.; SILVEIRA, V.C.P. Características quantitativas de carcaça de ovinos Santa Inês confinados alimentados com rações contendo diferentes níveis de caroço de algodão integral. Rev. Agron. Meio Amb., v.2, p.9-20, 2009. 